\title{
KLASIFIKASI EMOSI TOKOH ANTON DAN ANGEL DALAM NOVEL SURAT KECIL UNTUK TUHAN KARYA AGNES DANOVAR
}

\author{
Kamariah $^{1}$ dan Ayu Lestari ${ }^{2}$ \\ ${ }^{1)}$ Pendidikan Bahasa dan Sastra Indonesia \\ STKIP PGRI Banjarmasin \\ Jalan Sultan Adam, Komplek H. Iyus, No. 18 RT.23 Banjarmasin, \\ Kalimantan Selatan. Kode pos 70121 \\ email: kamariahm.pd@gmail.com \\ ${ }^{2)}$ Alumni Pendidikan Bahasa dan Sastra Indonesia \\ STKIP PGRI Banjarmasin \\ Jalan Sultan Adam, Komplek H. Iyus, No. 18 RT.23 Banjarmasin, \\ Kalimantan Selatan. Kode pos 70121 \\ email: Lestariayu84@gmail.com
}

\begin{abstract}
ABSTRAK
Penelitian ini mengkaji tentang klasifikasi emosi sesuai dengan karakter tokoh Anton dan Angel.Tujuan dari penelitian ini adalah (1) mendeskripsikan klasifikasi emosi tokoh Anton, dan (2) mendeskripsikan klasifikasi tokoh Angel dalam novel Surat Kecil Untuk Tuhan karya Agnes Davonar.

Pendekatan yang digunakan adalah pendekatan psiologis sastra.Jenis penelitian yang digunakan yaitu jenis penelitian kepustakaan.Sumber data yang digunakan dalam penelitian ini adalah novel yang berjudul Surat Kecil Untuk Tuhan karya Agnes Davonar.Novel ini diterbitkan oleh PT. Falcon Publishing dengan tebal buku 217 halaman.Teknik pengumpulan data yang digunakan dalam penelitian ini adalah studi teknik dokumentasi.Teknik Analisis Data menggunakan metode deskriptif analisis.

Simpulan penelitian ini adalah (1) Klasifikasi emosi tokoh Anton yaitu rasa bersalah, kesedihan, kebencian dan cinta. (2) Klasifikasi emosi tokoh Angel yaitu rasa bersalah, kesedihan, kebencian dan cinta. Kedua tokoh dalam novel ini berdasarkan penelitian memiliki klasifikasi emosi yang sama.
\end{abstract}

Kata Kunci: klasifikasi emosi, novel

\section{PENDAHULUAN}

Karya sastra yang berarti hasil aspirasi seseorang yang berupa buku sebagai wujud dari imajinasi yang direalisasikan dalam bentuk lisan maupun tulisan.Salah satu bentuk karya sastra yang berbentuk lisan seperti dongeng, legenda dan hikayat, sedangkan karya sastra yang berbentuk tulisan seperti novel, roman, cerpen dan sebagainya.Menurut Zaidan dkk (2007:97) "Karya sastra ialah hasil karya cipta manusia yang terlahir dari unsur pemikiran yang terdapat dalam suatu karya, mengandung nilai-nilai moral, religi, sosial maupun budaya".Sastra merupakan media bagi pengarang sebagai wadah untuk menuangkan pengalaman jiwa yang bersifat karya seni.Sebuah karya sastra menceritakan berbagai masalah kehidupan manusia di masyarakat dan lingkungan, hubungan sesama manusia dengan Tuhannya.Meskipun berupa khayalan, karya sastra tetap tidak 
bisa dianggap sebagai karya seni yang semu, karena dalam suatu karya sastra, khayalan, lamunan dan renungan dilakukan dengan penuh kesadaran.

Novel adalah jenis prosa yang mengandung unsur tokoh, alur, latar rekaan yang menggelarkan kehidupan atas dasar sudut pandang pengarang dan mengandung nilai kehidupan, diolah dengan teknik kiasan ragaan yang menjadi dasar konvensi penulis (Zaidan dkk, 2007:136).Novel adalah salah satu bentuk dari sebuah karya sastra dan merupakan sebuah karya fiksi yang menjelaskan tentang berbagai macam permasalahan dalam hidup manusia.Sebuah novel biasanya menceritakan tentang kehidupan manusia dan lingkungannya.

Di dalam sebuah novel, mengandung banyak cerita tentang kehidupan dan tentu saja banyak sekali emosi yang bisa dirasakan oleh pembaca dari berbagai tokoh yang memainkan peran di dalamnya.Tokoh adalah orang yang berperan di dalam cerita, atau sebagai sentral di dalam cerita.Dengan demikian dapat pula dikatakan bahwa tokoh adalah orang yang mengambil bagian dan mengalami peristiwa-peristiwa atau sebagian dari peristiwa-peristiwa yang digambarkan di dalam plot.Tokoh diklasifikasikan menjadi tiga bagian; 1) Tokoh protagonis, 2) Tokoh antagonis. 3) Tokoh tritagonis (Sumardjo, 2010:144).

Tokoh sering dibuat oleh novelis untuk tujuan-tujuan lain selain tujuan eksplorasi kepribadian dan psikologi manusia. Mereka bisa diciptakan untuk menceritakan sebuah kisah, untuk memberi contoh suatu keyakinan, untuk mendukung simbol-simbol tertentu dalam novel, atau sekedar untuk memperlancar perkembangan suatu plot tertentu dalam novel. (Kamariah, 2016: 38). Untuk menghidupkan tokoh tersebut maka dimasukkanlah pengklasifikasian emosi didalamnya, atau sering disebut dengan penokohan.

Dalam penokohan, si tokoh di masukkan emosi yang membalutnya sesuai dengan peran tokoh tersebut dalam cerita tersebut.Sarwono (2014:125) dalam bukunya menjelaskan bahwa "emosi adalah reaksi penilaian (positif atau negatif) yang kompleks dari sistem syaraf seseorang terhadap rangsangan dari luar atau dari dalam dirinya sendiri”.

Krech dalam Minderop (2013:39) menyatakan kegembiraan, kemarahan, ketakutan, dan kesedihan kerap kali dianggap sebagai emosi yang paling mendasar (primary emotions).Pola emosi remaja adalah sama dengan pola emosi kanak-kanak. Jenis emosi yang secara normal dialami adalah cinta/kasih sayang, gembira, amarah, takut dan cemas, cemburu, sedih, dan lain-lain. Perbedaan yang terlihat terletak pada macam dan derajat rangsangan yang mengakibatkan emosinya, dan khususnya pola pengendalian yang dilakukan individu terhadap ungkapan emosi remaja.Situasi yang membangkitkan perasaan-perasaan tersebut sangat terkait dengan tindakan yang ditimbulkannya dan mengakibatkan meningkatnya ketegangan. Selain itu kebencian atau perasaan benci (hate) behubungan erat dengan perasaan marah, cemburu, dan iri hati. Ciri khas yang menandai perasaan benci ialah timbulnya nafsu atau keinginan untuk menghancurkan objek 
yang menjadi sasaran kebencian. Perasaan benci bukan sekedar timbulnya perasaan tidak suka atau enggan yang dampaknya ingin menghindar dan tidak bermaksud menghancurkan. Sebaliknya, perasaan benci selalu melekat dalam diri seseorang, dan ia tidak akan pernah merasa puas sebelum menghancurkannya. Bila objek tersebut hancur, ia akan merasa puas. Perasaan bersalah dan menyesal juga termasuk kedalam klasifikasi emosi.

Novel Surat Kecil untuk Tuhan adalah salah satu novel yang di tulis oleh Agnes Davonar, diangkat dari kisah nyata seorang perempuan penderita kanker jaringan lunak pada tahun 2008.Terdapat dua tokoh utama dalam novel ini yaitu Anton dan Angel, kecelakaan yang merenggut nyawa kedua orangtua mereka menjadikannya yatim piatu, sejak saat itu mereka dirawat oleh Om Rudy yang kemudian menjadikan mereka pengamen di lampu merah.Dengan iming-iming mencarikan orangtua asuh, kedua kakak beradik itu kemudian bekerja setiap hari demi mencari uang tanpa pernah sadar kalau mereka sedang dimanfaatkan oleh Om Rudy.Suatu hari, Angel mengalami kecelakaan dan membutuhkan biaya besar untuk rumah sakitnya.Demi menyelamatkan Angel, Anton kemudian rela dijual kepada orang tua asuh oleh Om Rudy untuk menembus biaya rumah sakit adiknya.Om Rudy melarikan diri dan membiarkan Angel yang kemudian diasuh oleh seorang diplomat untuk tinggal di Australia. Kakak dan adik itu pun terpisah tanpa pernah sempat mengucapkan perpisahan, hanya sebuah surat kecil untuk Tuhan yang menjadi surat terakhir mereka kepada Tuhan agar kelak dipertemukan kembali.

Agnes Davonar adalah nama pena dari dua orang kakak beradik yang sukses menggapai puncak keemasan lewat dunia sastra. Nama asli dari Agnes Davonar ialah Agnes Li, perempuan yang lahir di Jakarta 8 Oktober 1990 dan Teddy Li, sang adik laki-laki yang lahir di Jakarta, 7 Agustus 1992 merupakan anak dari pasangan mendiang Ng Bui Cui dan Bong Nien Chin. Nama Agnes pada Agnes Davonar tentunya diambil dari nama Agnes sendiri, sedangakan nama Davonar, diambil dari inisial yang menggambarkan Teddy lewat orang terdekat Teddy.

Alasan peneliti menjadikan novel karya Agnes Davonar ini sebagai bahan penelitian adalah karena novel tersebut dapat membawa pembacanya merasakan emosi tokoh Anton dan Angel.Pembaca seolah di ajak masuk kedalam cerita novel tersebut. Selain itu berhubungan dengan klasifikasi emosi tentu erat kaitannya dengan diri pribadi maupun individu lain pada umumnya, emosi menjadi tolak ukur sikap dan perilaku seseorang dalam hidup, oleh sebab ini penting bagi peneliti untuk lebih dalam mengkaji tentang klasifikasi emosi yang terdapat dalam novel Surat Kecil Untuk Tuhan karya Agnes Davonar. Penelitian yang kurang lebih sama pernah dilakukan oleh peneliti terdahulu, diantaranya, Utami (2016) dengan judul “Klasifikasi Emosi Tokoh Cerita dalam Novel Rahasia Evalina Karya Belinda Gunawan: Kajian Psikologi Sastra”. Penelitian yang dilakukan Utami tersebut mengkaji tentang klasifikasi emosi tokoh dengan kajian psikologi sastra, 
meskipun dari segi judul nampak sama namun peneliti ini mengkaji lebih khusus hanya dengan dua tokoh utama saja.

Perbedaan antara penelitian terdahulu dan penelitian ini adalah dari segi judul, objek penelitian, dan fokus penelitian yang terdapat pada rumusan masalah dalam novel Surat Kecil Untuk Tuhan karya Agnes Davonar. Penelitian ini mengungkapkan bagaimana cerita kehidupan kedua kakak beradik yatim piatu yang merasakan seperti apa perihnya kehidupan.

\section{METODE}

Pendekatan yang digunakan peneliti adalah pendekatan psikologis sastra."Pendekatan psikologi pada dasarnya berhubungan dengan tiga gejala utama yaitu pengarang, karya sastra, dan pembaca, dengan pertimbangan bahwa pendekatan Psikologis lebih berhubungan dengan pengarang dan karya sastra” (Ratna, 2011:61).

Psikologi sastra adalah memahami aspek-aspek kejiwaan yang terkandung dalam suatu karya. Meskipun demikian, bukan berarti bahwa analisis psikologi sastra sama sekali terlepas dalam kebutuhan masyarakat. Sesuai dengan hakikatnya, karya sastra memberikan pemahaman terhadap masyarakat secara tidak langsung (Minderop, 2013:342).

Jenis penelitian yang digunakan yaitu jenis laporan penelitian kepustakaan.Penelitian kepustakaan adalah penelitian yang dilakukan hanya berdasarkan atas karya tertulis, termasuk hasil penelitian baik yang telah maupun yang belum dipublikasikan.

Sumber data yang digunakan dalam penelitian ini adalah novel Surat Kecil Untuk Tuhan karya Agnes Davonar diterbitkan oleh Falcon Publishing, Jakarta cetakan 2016 dengan tebal buku 217 halaman.Berupa fakta dalam bentuk satuan cerita yang terkait dengan klasifikasi emosi tokoh Anton dan Angel dalam novel Surat Kecil Untuk Tuhan karya Agnes Davonar.

Agar penelitian ini menjadi lebih terarah dan terfokus maka diperlukan indikator-indikator terkait rumusan masalah yang manjadi fokus penelitian. Untuk lebih jelasnya akan dijabarkan pada tabel di bawah ini:

\section{Tabel1}

Indikator Permasalahan Penelitian Klasifikasi Emosi Tokoh Anton dan Angel dalam Novel Surat Kecil Untuk Tuhan

Karya Agnes Davonar

\begin{tabular}{|l|l|l|l|l|}
\hline No & Permasalahan & \multicolumn{1}{|c|}{ Indikator } & \multicolumn{1}{|c|}{ Penanda } & \multicolumn{1}{|c|}{ Wujud } \\
\hline & & \multirow{3}{*}{ Tokoh Anton } & Rasa bersalah & Sikap \\
& & & Kesedihan & Fisik \\
& & Kebencian & Fisik \\
& & Cinta & Sikap \\
& & & \\
\hline
\end{tabular}




\begin{tabular}{|l|l|l|l|}
\hline Emosi & Tokoh Angel & Rasa bersalah & Sikap \\
& & Kesedihan & Fisik \\
& & Kebencian & Fisik \\
& & Cinta & Sikap \\
\hline
\end{tabular}

Permasalahan pada tabel 1 bertujuan agar lebih memudahkan peneliti untuk melakukan penentuan data.Pada kolom tabel permasalahan mencakup masalah-masalah yang ada dalam penelitian.Adapun indikator yakni berupa petunjuk atau keterangan yang mengarah pada rumusan masalah.Selanjutnya penanda merupakan tanda-tanda yang timbul dari suatu permasalahan.Terakhir yakni wujud, biasa berupa suatu benda yang dapat dilihat atau dirasakan yang digunakan untuk mencapai pemenuhan indikator.

Teknik Pengumpulan data, peneliti menggunakan teknik pustaka yaitu dengan menganalisis isi. Pada telaah ini peneliti membaca dan mencatat hal-hal yang berkaitan langsung dengan masalah dan tujuan penelitian. Datanya berupa novel, maka peneliti menelaah isi novel. Adapun langkahlangkahnya yaitu:

a. Membaca secara cermat novel Surat Kecil untuk Tuhan karya Agnes Davonar.

b. Merumuskan masalah.

c. Memilih dan menentukan data sesuai dengan masalah yang dirumuskan.

d. Mendeskripsikan data yang telah ditentukan.

Data dalam penelitian ini berupa fakta dalam bentuk satuan cerita yang terkait dengan klasifikasi emosi tokoh Anton dan Angel dalam novel Surat Kecil Untuk Tuhani karya Agnes Davonar. Data tersebut kemudian diberi kode tertentu guna memudahkan proses identifikasi dalam proses analisis data. Kode data yang digunakan dalam penelitian ini terdiri dari dua kode yang ditulis secara berurutan yaitu:

a. Inisial judul novel ditulis dengan dua huruf kapital dan diakhiri dengan titik, penulisan inisial judul (kode: ST).

b. Inisial dari bentuk Tokoh Anton dan Tokoh Angel ditulis dengan dua huruf kapital dan diakhiri dengan titik. Penulisan inisial tersebut terdiri dari akhlak (kode: TA) dan kepribadian (kode: TE).

c. Nomor urut data ditulis dengan angka kecil di bawah inisial bentuk Tokoh Anton dan Tokoh Angel.

d. Tahun terbit novel ditulis setelah penulisan nomor urut data diberi tanda titik dua $(:)$ dan diikuti dengan titik.

e. Nomor halaman dimana data dikutip dan ditulis dengan angka dan diakhiri dengan angka. Untuk data yang terletak pada dua halaman yang menyambung maka diberi garis hubung. 
Instrumen penelitian dalam novel yang berjudul Surat Kecil Untuk Tuhan karya Agnes Davonar yang dilakukan oleh peneliti ini merupakan penelitian teks sehingga instrumen yang digunakan adalah teks itu sendiri, yakni kutipan-kutipan dari novel dengan judul tersebut dengan membuat tabel yang berisi nomor, kode data, uraian data, deskripsi, dan interpretasi pada kutipankutipan teks yang dibutuhkan, sehingga memudahkan peneliti untuk menginterpretasikan data tersebut.

Tabel 2

Instrumen Penjaringan Data dalam Novel Surat Kecil Untuk Tuhan

Karya Agnes Davonar

\begin{tabular}{|c|c|c|c|c|}
\hline No & Kode Data & Uraian Data & Deskripsi & Interpretasi \\
\hline 1 & ST.TA $: 2016.9$ & & & \\
\hline 2 & ST.TE $_{1}: 2016.19$ & & & \\
\hline
\end{tabular}

Keterangan :
a. ST
$=$ Surat Kecil Untuk Tuhan
b. TA
$=$ Tokoh Anton
c. TE
$=$ Tokoh Angel

Pengelompokan kode tabel 2 dimaksudkan untuk memudahkan mengumpulkan data dan untuk lebih mudah memahami dalam memberi kode data. Berikut akan diuraikan maksud dari memberikan kode tersebut.

a. ST menunjukkan judul novel Surat Kecil Untuk Tuhan karya Agnes Davonar yang dijadikan objek penelitian.

b. $\mathrm{TA}_{1}$ menunjukkan data pertama bentuk Tokoh Anton yang terdapat dalam novel Surat Kecil Untuk Tuhan karya Agnes Davonar.

c. $\mathrm{TE}_{1}$ menunjukkan data pertama bentuk Tokoh Angel yang terdapat dalam novel Surat Kecil Untuk Tuhan karya Agnes Davonar

d. 2016 menunjukkan tahun terbit novel yang diteliti.

e. Angka setelah tahun 2016 menunjukkan halaman data yang terdapat dalam novel Surat Kecil

Untuk Tuhan karya Agnes Davonar.

Teknik analisis data menggunakan metode deskriptif analisis. Metode deskriptif analisis dilakukan dengan cara mendeskrisikan fakta-fakta yang kemudian disusul dengan analisis (Ratna, 2011:53). Fakta-fakta yang dimaksud adalah data yang diperoleh dalam novel Surat Kecil Untuk Tuhan karya Agnes Davonar berupa fakta dalam bentuk satuan cerita yang menjelaskan tentang Tokoh Anton dan Angel. 
Adapun analisis isi lebih mencakup pada prosedur khusus pemerosesan data ilmiah. Untuk menganalisis data sesuai rumusan masalah pada penelitian ini maka langkah-langkah yang diambil adalah sebagai berikut:

\section{a. Interpretasi}

Interpretasi data merupakan tahap untuk memaknai data yang ada sesuai dengan pandangan peneliti terhadap data yang berkaitan dengan klasifikasi emosi Tokoh Anton dan Angel dalam novel Surat Kecil Untuk Tuhan karya Agnes Davonar.

b. Analisis data

Data yang berkaitan dengan Tokoh Anton dan Angel dalam novel Surat Kecil Untuk Tuhan karya Agnes Davonar, kemudian dianalisis dengan teori yang digunakan.

c. Menyimpulkan

Setelah dilakukan analisis, langkah selanjutnya adalah menyimpulkan hasil analisis sesuai dengan rumusan masalah yang terdapat dalam penelitian.

\section{HASIL DAN PEMBAHASAN}

Dalam pembahasan klasifikiasi emosi yang terdapat pada tokoh Anton dan Angel dalam novel surat kecil untuk tuhan yaitu rasa bersalah, kesedihan, kebencian dan cinta.

\section{Tokoh Anton}

Anton adalah kakak dari Angel, dia sangat menyayangi Angel, Anton juga merupakan sosok pengganti orangtua dari Angel yang telah meninggal. Anton sangat bertanggungjawab dan rela melakukan apa saja demi Angel. Berikut merupakan kutipan dalam novel Surat Kecil Untuk Tuhan yang menggambarkan betapa Anton sangat menyayangi Angel.

"Sabar ya, Adik..kalau hujannya sudah reda nanti kakak cariin makanan. Sang kakak tersenyum, tangannya membelai kepala Angel dengan penuh hangat" (ST.TA 1 :2016.3).

\section{a. Rasa Bersalah}

Rasa bersalah datang ketika seseorang telah memahami mengenai mana benar dan salah.Bohong merupakan suatu hal yang dapat memunculkan rasa bersalah, berbohong demi menjaga perasaan seseorang kadang membuat lupa bahwa perbuatan itu tidaklah benar untuk dilakukan. Seperti kutipan berikut.

“Anton hanya bisa berharap Angel tidak kecewa. Ia sadar betul kalau sepeser pun uang ia tidak punya untuk membelikan apa yang adiknya mau" (ST.TA 2 :2016.4).

Perasaan sakit yang teramat dalam adalah ketika mengetahui orang yang sangat kita cintai meninggalkan kita untuk selamanya dan ini juga merupakan gambaran dari rasa bersalah seperti berikut. 
"Ayah dan Ibu kalian telah meninggal...Suara pelan Bibi Feli saat mengucapakan kalimat itu terasa seperti teriakan di telinga Anton. Ia tak mau mempercayainya" (ST.TA 3 :2016.6).

Menangis terkadang menjadi salah satu cara untuk sedikit meringankan rasa sakit kerena kecewa terhadap keadaan, itu yang di lakukan Anton dalam kutipan berikut.

"Anton hanya terus menangis dan menangis selayaknya bocah yang seharusnya tidak memiliki beban seberat itu dalam hidupnya" (ST.TA 4 :2016.7).

\section{b. Kesedihan}

Kesedihan adalah suatu emosi yang ditandai oleh perasaan tidak beruntung, kehilangan, dan ketidakberdayaan. Saat sedih, manusia sering menjadi lebih diam, kurang bersemangat, dan menarik diri. Ada perasaan sedih ketika seseorang gagal menjaga sesuatu yang dianggap sangat berharga dalam hidupnya, itu yang di rasakan Tokoh Anton dalam kutipan berikut.

“Anton pun menyadari apa yang terjadi pada adiknya selama ia pergi, penderitaan yang dijalani tanpa sepengetahuannya. Rasa sakit yang dialami sang adik kini juga ia alami. Tapi ia hanya bisa bertahan, menahan sakit sembari memikirkan apa yang harus ia lakukan (ST.TA $5: 2016.15)$.

Ketika peristiwa yang sangat tidak diharapkan terjadi maka seseorang akan spontan keluar dari kebiasaannya, bahkan pikiran tenang pun akan berubah menjadi kecemasan saat mendapati orang yang sangat di kasihi tidak berdaya berada di hadapan, seperti kutipan berikut.

"Anton berteriak memanggil Angel berkali-kali, berusaha menyadarkannya dan meminta pertolongan. Orang-orang disekitar tidak tahu harus berbuat apa untuk kedua kakak beradik yang malang itu. Terlintas dibenak mereka" (ST.TA 6 :2016.88).

\section{c. Kebencian}

Kebencian merupakan emosi yang sangat kuat dan melambangkan ketidaksukaan, permusuhan, atau antipati untuk seseorang, sebuah hal, barang, atau fenomena. Hal ini juga merupakan sebuah keinginan untuk, menghindari, menghancurkan atau menghilangkannya.Kecewa dan kebencian memunculkan rasa sakit dan penyesalan dalam kehidupan, kenyataan yang terjadi sangat sulit di terima, seperti kutipan berikut.
"Anton menangis sejadi-jadinya. Angel yang tak mengerti keadaan, menjadi panik dan ikut menangis keras. Rasa sedih sekaligus kecewa terhadap apa yang terjadi membuat Anton merasa tak bisa menerima kenyataan" (ST.TA 7 :2016.7).

\section{d. Cinta}

Cinta adalah sebuah perasaan yang diberikan oleh Tuhan pada sepasang manusia untuk saling saling mencintai, saling memiliki, saling memenuhi, saling pengertian.Rasa kasih antara 
kakak dan adik tidak bisa dipungkiri begitu kuat, tidak ada yang dapat menggantikan cinta seorang saudara terhadap saudaranya sendiri, seperti kutipan berikut.

"Biasanya, setelah membantu mengangkat barang bawaan belanja pelanggan, Anton akan mendapatkan uang receh yang ia kumpulkan diamdiam dari bibinya. Uang itu kemudian sebagian ia belikan coklat atau jajanan untuk diberikan pada Angel saat pulang. Bila Anton pulang dengan coklat dan manisan, Angel akan begitu gembira dan suka cita menyambut setelah sekian lama menunggu dirumah" (ST.TA 8 :2016.9).

Komunikasi adalah hal penting dalam kehidupan, oleh karena itu selalulah berusaha untuk menyempatkan berbincang dan berbagi keluh kesah dengan orang terdekat, seperti berikut.

"Adik, kalau ada yang mau Adik ceritakan sama kakak, cerita semuanya jangan ragu ya. Kakak selalu ada untuk kamu. Kakak akan melindungi Adik dari siapapun yang jahat sama kamu. Oke?" (ST.TA9:2016.11).

Pelukan hangat penuh cinta akan membuat seseorang menjadi tenang dalam beberapa waktu, seperti berikut.

"Sesekali Angel mengeluh kepada kakaknya, yang langsung memeluk sang adik agar terasa lebih hangat" (ST.TA $10: 2016.31)$.

\section{Tokoh Angel}

Angel adalah sosok yang penyayang, angel sangat menurut apapun yang di katakan oleh Anton Kakaknya, Angel dalam novel ini memiliki dua bagian karakter yang sangat berbeda, Angel kecil memiliki sikap sangat manja dan selalu bergantung pada kakaknya Anton. Tetapi angel dewasa tumbuh menjadi wanita yang kuat, cerdas dan mempunyai mimpi yang sangat mulia yaitu menjaga anak-anak jalanan, menjaga hak anak-anak tersebut agar tetap bisa mendapatkan kehidupan yang layak. Angel dewasa menjadi seorang pengacara di Australia dan kemudian kembali ke indonesia untuk mencari di mana keberadaan Anton sang kakak yang sangat dia sayangi.

\section{a. Rasa Bersalah}

Rasa bersalah adalah emosi hati nurani kita bahwa kita telah melakukan sesuatu yang salah.Anggel takut melihat kakaknya menangis.Dia takut penyebab kakaknya menangis adalah karena kesalahannya.

"Kakak kenapa menangis? Adik takut" (ST.TE 1 :2016.7).

Lupa ingatan membuat Angel melupakan semua yang terjadi di masa lalunya, termasuk sang kakak, namun suatu peristiwa membuatnya kembali dapat mengingat semua, penyesalan dan rasa bersalah itu pun muncul, berikut kutipannya. 
"Air mata Angel kini terjatuh membasahi kertas yang ia pegang. Dari balik pintu kamarnya, kedua orangtua angkat Angel hanya bisa melihat anak itu dengan penuh kesedihan. Mereka sadar, Angel sangat berharap bisa bertemu kakaknya" (ST.TE 2 :2016.124).

\section{b. Kesedihan}

Kesedihan dapat menyebabkan reaksi fisik seperti menangis, sulit tidur, nafsu makan yang buruk, dan juga reaksi emosional, seperti penyesalan.

Beranjak dari amnesia yang di alami Angel tidak membuat kebahagiaan menghampiri, malah rasa bersalah, kesedihan dan rasa sakit yang teramat dalam sedang di rasakan Angel, hati dan pikirannya begitu kacau bingung dengan apa yang sedang terjadi. Di sisi lain saat ini Angel telah mendapatkan orangtua angkat yang benar-benar dapat merawatnya dengan baik, namun disisi lain Angel kehilangan sosok pelindung yaitu Anton sang kakak. Berikut adalah kutipan kegundahan Angel.

"Kakak...ayah dan ibu kapan pulang?Adik lapar banget?" (ST.TE 3 :2016.2).

"Angel pun memeluk ayah dan ibunya dengan penuh tangis. Mereka membalas pelukan Angel sambil membelai rambutnya dengan lembut, mengasihi Angel yang hidupnya selalu di terpa derita" (ST.TE 4 :2016.124).

Di saat semua orang memiliki mimpi yang sangat luar biasa dan penuh dengan angan, Angel hanya punya satu mimpi dan itu sangat jauh berbeda dengan anak lain seusiannya, dia hanya ingin cepat di pertemukan dengan Anton kakaknya, berikut kutipannya.

"Angel..apa impian dan cita-cita kamu jika sudah besar nanti? saya ingin bertemu dengan kakak, Miss. Seisi kelas menatap Angel dengan heran, terutama gurunya" (ST.TE $5: 2016.125)$.

\section{c. Kebencian}

Kenyataan terkadang berjalan tidak sesuai dengan apa yang menjadi harapan selama ini, mimpi dan harapan baik yang tumbuh seketika sirna saat mengetahui apa yang sebenarnya terjadi, kebencian terhadap keadaan membuat semua yang dilakukan menjadi tidak berarti, seperti berikut.

“Air matanya jatuh tanpa tertahan. Kakak yang Angel cari selama ini telah meninggal. Anton disebut sebagai korban pembunuhan bersama anakanak lain dalam kasus praktek illegal jual beli organ tubuh manusia. Jasadnya ditemukan terkubur disebuah kelinik" (ST.TE 3 :2016.129). 


\section{d. Cinta}

Cinta itu menjaga dan saling melindungi, bahkah sampai rela berkorban demi menjaga orang yang di cintai dari bahaya, seperti berikut.

"Maafkan adik tidak berani cerita.Adik Cuma tidak ingin kakak dipukul paman juga. Jadi adik bertahan disini” (ST.TE 4 :2016.16).

Cinta adalah kata paling abstrak yang pernah ada, definisinya tergantung keadaan hati orang yang merasakannya, namun satu hal yang pasti yaitu cinta selalu memunculkan kebahagiaan, seperti kutipan berikut.

"Angel berjalan meninggalkan ibunya menuju kamar. Ia berbaring di ranjang sambil terus menebar senyum tiada henti. Sebuah pesan terkirim dari Martin Wira, menanyakan apakah Angel sudah pulang kerumah dengan selamat. Gadis itu pun membalas perhatian dari pria yang varu saja ia kenal dengan penuh kebahagiaan. Hari itu menjadi awal dari hubungan mereka yang semakin akrab dan kerap mengahabiskan waktu bersama" (ST.TE $5: 2016.144)$.

Saat dua hati telah menemukan rasa nyamannya, maka keluarga adalah tempat selanjutnya agar cinta menjadi lebih indah, memperkenalkan pasangan kepada kedua orangtua membuat hati menjadi lebih bahagia dari sekedar menjalani cinta hanya berdua, berikut kutipannya.

"Sebulan setelah pertemuan pertama di kampus, Angel mengenalkan Mertin Wira kepada orangtuanya. Soraya dan Edwards bersikap sangat hangat kepada pemuda yang ramah itu" (ST.TE 6 :2016.145).

Romansa romantis muncul dalam perjalanan indah cinta, banyak cara untuk saling membahagiakan, berikut kutipannya.

"Wira berjanji akan membawa Angel untuk bertemu orangtuanya nanti, keduanya melanjutkan hubungan dengan penuh kasih sayang dalam sebuah lukisan cinta setelah Wira meminta Angel untuk menjadi kekasihnya dalam sebuah makan malam indah. Dengan menggenggam setangkai mawar merah, Wira menyatakan cinta kepada Angel, yang nyaris tersedak roti karena kaget. Ia terharu melihat cara Wira menembaknya dengan begitu romantis". (ST.TE 7 :2016.14).

\section{SIMPULAN}

Berdasarkan kajian yang telah dilakukan terhadap novel Surat Kecil Untuk Tuhan Karya Agnes Davonar, maka dapat dikemukakan beberapa simpulan sebagai berikut:

Klasifikasi emosi tokoh Anton yaitu (1) rasa bersalah yang datang ketika seseorang telah memahami mengenai mana benar dan salah, (2) kesedihan emosi yang ditandai oleh perasaan tidak beruntung, (3) kebencian merupakan emosi dari rasa kehilangan yang sangat kuat dan 
melambangkan ketidaksukaan, permusuhan, atau antipati untuk seseorang, sebuah hal, barang, atau fenomena dan ketidakberdayaan dan (4) cinta adalah sebuah perasaan yang diberikan oleh Tuhan pada sepasang manusia untuk saling saling mencintai, saling memiliki, saling memenuhi, saling pengertian.

Klasifikasi emosi tokoh Angel yaitu (1) rasa bersalah emosi hati nurani bahwa kita telah melakukan sesuatu yang salah, (2) kesedihan dapat menyebabkan reaksi fisik seperti menangis, sulit tidur, nafsu makan yang buruk, dan juga reaksi emosional, seperti penyesalan, (3) kebencian ialah sebuah perasaan yang timbul dari ketidak sukaan terhadap suatu hal, (4) cinta mempunyai banyak arti namun maknanya hanya satu yaitu saling mengasihi.

\section{SARAN}

Peneliti memberikan saran sebagai berikut:

a. Diharapkan agar penikmat karya sastra dapat mengapresiasi novel Surat Kecil Untuk Tuhan Karya Agnes Davonar sebagai suatu pelajaran serta gambaran kehidupan, karena dalam novel ini banyak nilai-nilai kehidupanbaik itu di keluarga maupun sosial.

b. Disarankan agar peneliti lain yang akan melakukan kajian tentang klasifikasi emosi tokoh agar lebih mendalami tentang karya sastra yang akan diteliti, karena klasifikasi emosi memiliki cakupan yang sangat luas.

\section{DAFTAR RUJUKAN}

Davonar, Agnes. 2016. Surat Kecil Untuk Tuhan. Jakarta:Falcon Publising.

Minderop, Albertine. 2013. Psikologi Sastra. Jakarta: Yayasan Pustaka Obor Indonesia.

Kamariah.2016. Profil Tokoh Utama Wanita dalam Novel Serenade Biru Dinda Karya Asma Nadia.Banjarmasin: Jurnal LENTERA STKIP PGRI BanjarmasinVolume 11, Nomor. 2 Tahun 2017.dapat diakses pada alamat http://ejurnal.stkipbjm.ac.id/index.php/jpl/article/view/181

Ratna, Kutha Nyoman. 2011. Teori, Metode, dan Teknik Penelitian Sastra. Yogyakarta: Pustaka pelajar.

Sarwono, SarlitoWirawan. 2014. Pengantar Psikologi Umum. Jakarta: Rajawali Pers.

Sumardjo, Jakob. 2010. Apresiasi Kesusastraan. Jakarta: PT Gramedia Pustaka Utama.

Zaidan, Abdul, dkk. 2007.Kamus Istilah Sastra. Jakarta: Balai Pustaka. 